\title{
Investigation of changes in compressed moso bamboo (Phyllostachys pubescens) after hot-press molding
}

\author{
$\mathrm{Li} \mathrm{Gao}^{1} \cdot$ Wenjing Guo ${ }^{1} \cdot$ Shupin Luo ${ }^{1}$ (]
}

Received: 7 April 2018 / Accepted: 8 June 2018 / Published online: 12 July 2018

(c) The Japan Wood Research Society 2018

\begin{abstract}
In this study, molding moso bamboo strips to a curved shape using hot-press molding operation was explored. Bamboo strips with different thickness and moisture content (MC) were subjected to press molding under $120-210{ }^{\circ} \mathrm{C}$ for different time. Changes in the chemical components of bamboo were analyzed by Fourier-transform infrared spectroscopy (FTIR). Effect of $\mathrm{MC}$ on thermal mechanical behavior of bamboo was investigated using dynamic mechanical analysis (DMA). Results showed that the influencing degree of four variables on compression and recovery ratios decreased as: temperature $>$ time $>$ thickness $>$ MC. Compression ratio increased and recovery ratio decreased dramatically when pressing temperature exceeded $180^{\circ} \mathrm{C}$. FTIR analysis indicated that polysaccharide (especially hemicelluloses) underwent a progressive thermal degradation during compression at 180 and $210^{\circ} \mathrm{C}$ for $40 \mathrm{~min}$, whereas relative content of lignin increased. DMA results showed that bamboo samples with a higher $\mathrm{MC}$ had a lower storage modulus value, confirmed water had a plasticizing effect. The loss factor of bamboo with higher MC (12 and 16\%) exhibited two major transitions centred around $100{ }^{\circ} \mathrm{C}\left(\alpha_{1}\right)$ and $50{ }^{\circ} \mathrm{C}$ $\left(\alpha_{2}\right)$, respectively. The temperature of these $\alpha$ transitions kept almost unchanged as moisture level increased from 12 to $16 \%$. These findings provide fundamental information for the future preparation of curved bamboo as profiled components in engineered products.
\end{abstract}

Keywords Bamboo $\cdot$ Hot-press molding $\cdot$ Compression recovery ratio $\cdot$ Thermal degradation $\cdot$ Transition

\section{Introduction}

Bamboo is an under-utilized material that could be used more efficiently in structural or engineered products analogous to glue-laminated wood, oriented strand board and plywood [1]. As a renewable and inexpensive material, bamboo has the potential to be used as a substitute for wood or expensive timber in bamboo producing countries [2]. Bamboo has a unique fiber-reinforced composite-like structure, consisting of vascular bundles, relatively large arrangements of dense sclerenchyma cells supporting vessels, in a matrix of low density parenchyma [3].

As an existing technique for improving strength properties, compression has been performed on solid wood and bamboo, during which the material is densified by properly

Shupin Luo

luosp@caf.ac.cn

1 Research Institute of Wood Industry, Chinese Academy of Forestry, No. 1 Dongxiaofu, Haidian District, Beijing 100091, China heating and a compression force $[4,5]$. However, it is difficult to obtain such modified materials with curved or other complicated shapes because this technique is often performed on a plate-pressing. Pressing the materials in molds is one method to make curved products in large numbers. Molding method has long been used for fabrication of wood and other biomass-based composites from powder, particle, or veneer forms. However, the fiber structure of bamboo, which is mechanically beneficial, is damaged in these forms. Bamboo has conventionally been processed by cutting and gluing, which limits the shape of the products and the productivity. It is necessary to investigate changing the shape of bamboo strips using the mold pressing operation, which provides the potential to manufacture profiled bamboo components for utilization in engineering products.

The feasibility of molding solid wood has been examined by Yamashita et al. [6]. They found that the pliability of wood improves as its MC increases, which is due to the softening of hemicellulose and lignin in the presence of water. It is known that wood undergoes elastic-visco-plastic deformation during compression. When the compressed sample is 
moistened and heated in the absence of any external force, it generally returns to its original shape, to a degree depending on the process parameters, i.e., temperature, time and MC during the compression [7]. This phenomenon is known as compression-set recovery. Hydrothermal treatment is well known as an effective method of wood plasticization. It reduces the softening temperature of the amorphous components, which is also an important process to fix the shape of compressed and bent wood [8]. During compression at elevated temperature, the presence of water serves to plasticize cell wall components, while the effect of heat is to bring the cell wall above its glass transition temperature, which has been reduced by plasticization effect [1].

The deformation and fixation of compressed wood have been studied and widely reported [9-12]. However, the information on basic properties of compressed bamboo for supporting higher utilization of such materials are still lacking, especially those related to softening behavior, deformations and setting of compressed conditions. We, therefore, studied the practice of molding bamboo strips to a curved shape with a small radius of curvature using this hot-press molding operation. In this paper, bamboo strips with different thicknesses and $\mathrm{MC}$ were subjected to press molding under $120-210{ }^{\circ} \mathrm{C}$ for different time. The influence of these variables (temperature, time, MC and thickness) on compression and recovery ratio, color changes, microstructure, mass loss, chemical changes and thermal-mechanical behavior were investigated to give fundamental information on bamboo press molding under hydrothermal conditions.

\section{Experimental section}

\section{Materials}

Moso bamboo (Phyllostachys pubescens) aged 3-4 years was obtained from Fujian province. Tangentially oriented strips (22 mm tangential, $100 \mathrm{~mm}$ longitudinal) with different thickness $(0.9,2.3,3.6$ or $4.9 \mathrm{~mm}$ radical $)$ were cut from the moso culm section (Fig. 1). The average density of the air-dried strips is $700 \mathrm{~kg} / \mathrm{m}^{3}$.

\section{Determination of compressive deformation and recovery ratios of bamboo}

The bamboo specimens were conditioned to arrive at 4,8 , 12 , or $16 \% \mathrm{MC}$ in a humidity chamber, respectively. Then they were wrapped in aluminum foil and placed in a circular arc mold with radius of $210 \mathrm{~mm}$ (Fig. 2). Hot pressing was carried out in the radial direction at a pressure of 1.5-2.0 MPa at different temperatures $(120,150,180$ or $210{ }^{\circ} \mathrm{C}$ ) for $10,20,30$ or $40 \mathrm{~min}$, respectively. When reaching the prescribed press time, the compressed samples were

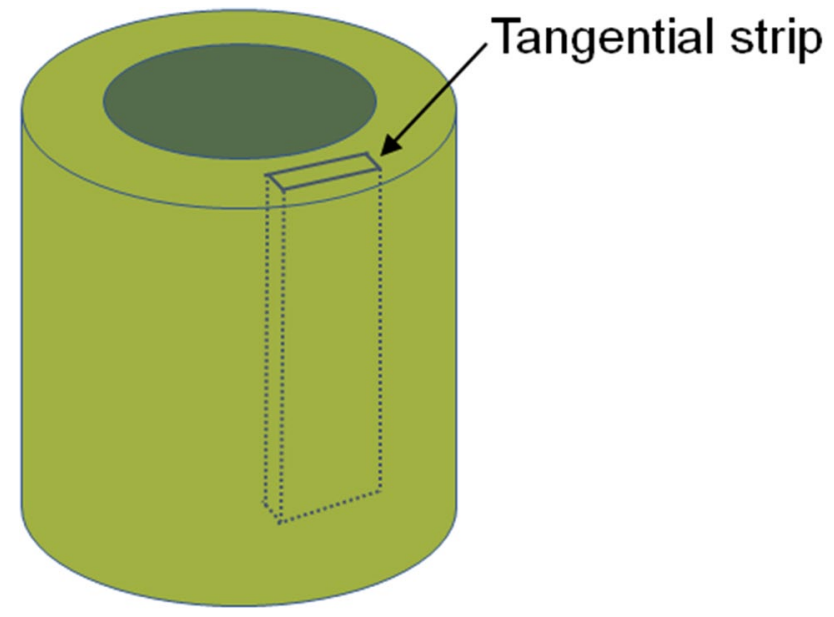

Fig. 1 Tangentially oriented strips cut from moso bamboo culm

taken out of the mold, and then conditioned at $20{ }^{\circ} \mathrm{C}$ and $65 \%$ relative humidity in a humidity chamber for 3-4 weeks.

The influence of different variables, namely specimen thickness, MC, hot-press temperature and time on deformation and recovery ratio of bamboo specimen was simultaneously evaluated using Taguchi's orthogonal array $L_{16}$ ( $4^{4}, 4$ factors and 4 work levels). Table 1 demonstrates the different variables evaluated and the conditions chosen for the different experimental groups. 12 replicates were used in each condition and the thickness at three points in each specimen was measured to calculate the average values. The compression ratio $\left(R_{\mathrm{c}}\right)$ and recovery ratio $\left(R_{\mathrm{r}}\right)$ were determined as follows:

$R_{\mathrm{c}}=\frac{T_{0}-T_{\mathrm{c}}}{T_{\mathrm{c}}} \times 100 \%$,

$R_{\mathrm{r}}=\frac{T_{\mathrm{f}}-T_{\mathrm{c}}}{T_{0}-T_{\mathrm{c}}} \times 100 \%$,

where $T_{0}$ and $T_{\mathrm{c}}$ are the thickness before and after compression, respectively, and $T_{\mathrm{f}}$ is the thickness after equilibrium.

\section{Microscopic observations}

Cross-section samples were cut from the bamboo specimens before and after compression. The fractured surface was coated with gold and observed using a Hitachi S-3400N scanning electron microscope with an acceleration voltage of $5 \mathrm{kV}$.

\section{Mass loss measurement}

The mass loss of specimens after hot-press molding was estimated according to Eq. (3): 

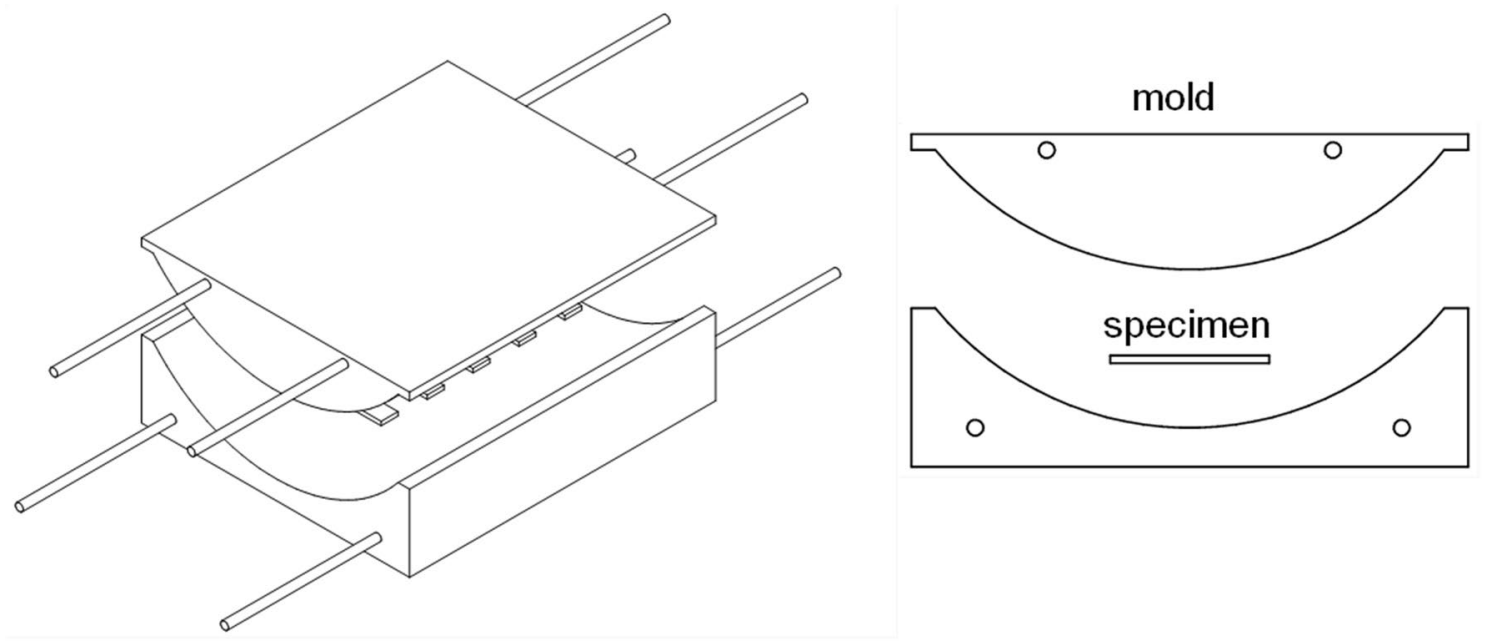

Fig. 2 Schematic of the circular arc mold used for compression

Table 1 The influence of different compression parameters determined by Taguchi's orthogonal array $L_{16}\left(4^{4}\right)$ on compression and recovery ratios of bamboo

\begin{tabular}{llrllcll}
\hline Coding & $\begin{array}{l}\text { Thickness } \\
(\mathrm{mm})\end{array}$ & MC $(\%)$ & $\begin{array}{l}\text { Tempera- } \\
\text { ture }\left({ }^{\circ} \mathrm{C}\right)\end{array}$ & Time $(\mathrm{min})$ & $\begin{array}{l}\text { Compression } \\
\text { ratio }(\%)\end{array}$ & $\begin{array}{l}\text { Recovery } \\
\text { ratio }(\%)\end{array}$ & Mass loss $(\%)$ \\
\hline 1 & 0.9 & 4 & 120 & 10 & 5.0 & 98.2 & 0.37 \\
2 & 0.9 & 8 & 180 & 40 & 17.5 & 19.6 & 3.95 \\
3 & 0.9 & 12 & 210 & 20 & 19.1 & 15.5 & 6.68 \\
4 & 0.9 & 16 & 150 & 30 & 8.6 & 58.4 & 6.23 \\
5 & 2.3 & 4 & 150 & 20 & 2.3 & 99.7 & 0.54 \\
6 & 2.3 & 8 & 210 & 30 & 23.1 & 8.8 & 6.45 \\
7 & 2.3 & 12 & 180 & 10 & 6.5 & 48.4 & 3.44 \\
8 & 2.3 & 16 & 120 & 40 & 9.6 & 27.2 & 3.12 \\
9 & 3.6 & 4 & 180 & 30 & 3.9 & 57.5 & 1.79 \\
10 & 3.6 & 8 & 120 & 20 & 2.4 & 63.8 & 0.87 \\
11 & 3.6 & 12 & 150 & 40 & 7.3 & 39.1 & 2.73 \\
12 & 3.6 & 16 & 210 & 10 & 18.2 & 13.2 & 4.67 \\
13 & 4.9 & 4 & 210 & 40 & 25.8 & 6.0 & 7.79 \\
14 & 4.9 & 8 & 150 & 10 & 5.4 & 46.7 & 1.36 \\
15 & 4.9 & 12 & 120 & 30 & 11.4 & 24.9 & 2.33 \\
16 & 4.9 & 16 & 180 & 20 & 11.3 & 24.1 & 3.89 \\
\hline
\end{tabular}

$M C$ moisture contents

Mass loss $(\%)=\frac{w_{1}-w_{0}}{w_{0}} \times 100 \%$,

where $w_{0}$ and $w_{1}$ represent the mass of sample before and after compression on oven-dry basis, respectively.

\section{Fourier transform infrared spectroscopy (FTIR) analysis}

Chemical changes in the bamboo samples before and after compression were characterized by FTIR (NEXUS 870,
Nicolet). The spectra were recorded with $4 \mathrm{~cm}^{-1}$ resolution at a wavenumber range of $4000-400 \mathrm{~cm}^{-1}$.

\section{Dynamic mechanical analysis (DMA)}

Specimens $(60 \mathrm{~mm} \times 12 \mathrm{~mm} \times 2.25 \mathrm{~mm}, \mathrm{~L} \times \mathrm{T} \times \mathrm{R})$ were conditioned to reach 8,12 and $16 \% \mathrm{MC}$, respectively, and then wrapped in aluminum foil. The oven-dried specimens with $0 \% \mathrm{MC}$ were also tested as control. The temperaturedependent dynamic thermomechanical properties were tested using a dynamic mechanical analyzer (DMA 2980, TA) in a three-point bending mode. The experiments were 
conducted from 30 to $150{ }^{\circ} \mathrm{C}$ at $3{ }^{\circ} \mathrm{C} / \mathrm{min}$ with a frequency of $1 \mathrm{~Hz}$. The displacement amplitude was set at $15 \mu \mathrm{m}$.

\section{Statistical analysis}

Analysis of variance (ANOVA) and analysis of range (ANOR) were performed for compression and recovery ratios and mass loss data using SAS software (Version 8.0, SAS Institute, Cary, NC, USA). If the $P$ value is less than 0.05 , it indicates that values are significantly different at a significance level of $5 \%$.

\section{Results and discussion}

\section{Compression and recovery ratios}

The compression and recovery ratios of compressed bamboo for different conditions are shown in Table 1. Both the specimen conditions (thickness and MC) and compression parameters (temperature and time) had significant effects on the compression and recovery ratio. ANOVA revealed that the influencing degree of four variables on compression ratio decreased as: temperature $>$ time $>$ thickness $>M C$, and recovery ratio exhibited a similar decreasing trend. Generally, compression ratio increased significantly with prolonging compression time. Furthermore, compression at higher temperature resulted in lower recovery ratio after equilibrium. The highest compression ratio and lowest recovery ratio were obtained in specimen with $4.9 \mathrm{~mm}$ thickness and $4 \% \mathrm{MC}$ that was pressed at $210{ }^{\circ} \mathrm{C}$ for $40 \mathrm{~min}$.

The significance of difference between four levels for each factor was determined by ANOR (Fig. 3). For hotpress temperature, 120 and $150{ }^{\circ} \mathrm{C}$ showed negligible difference on compression ratio, $180{ }^{\circ} \mathrm{C}$ led to a remarkable increase, and $210^{\circ} \mathrm{C}$ resulted in a compression ratio over $21 \%$ (Fig. 3a). Very high recovery ratio was observed for samples compressed at low temperatures. The recovery ratio decreased dramatically when pressing temperature exceeded $180{ }^{\circ} \mathrm{C}$ (Fig. 3b). This indicated that higher temperature was beneficial for compression deformation fixation. Hot-press time exhibited a similar trend with temperature. The samples with 0.9 and $4.9 \mathrm{~mm}$ thickness showed higher compression ratios than medium thickness. This phenomenon is probably due to the unique microstructure of bamboo culm, which consists of many vascular bundles surrounded by bundle sheaths, reinforcing the bamboo culm. The vascular bundles are distributed densely in the outer side of the culm wall, and sparsely in the inner side $[3,13]$. Therefore, the outer region of bamboo possesses a higher density and strength than the inner region. The thicker samples contain more inner parts of culm wall, thus giving larger deformation when subjected
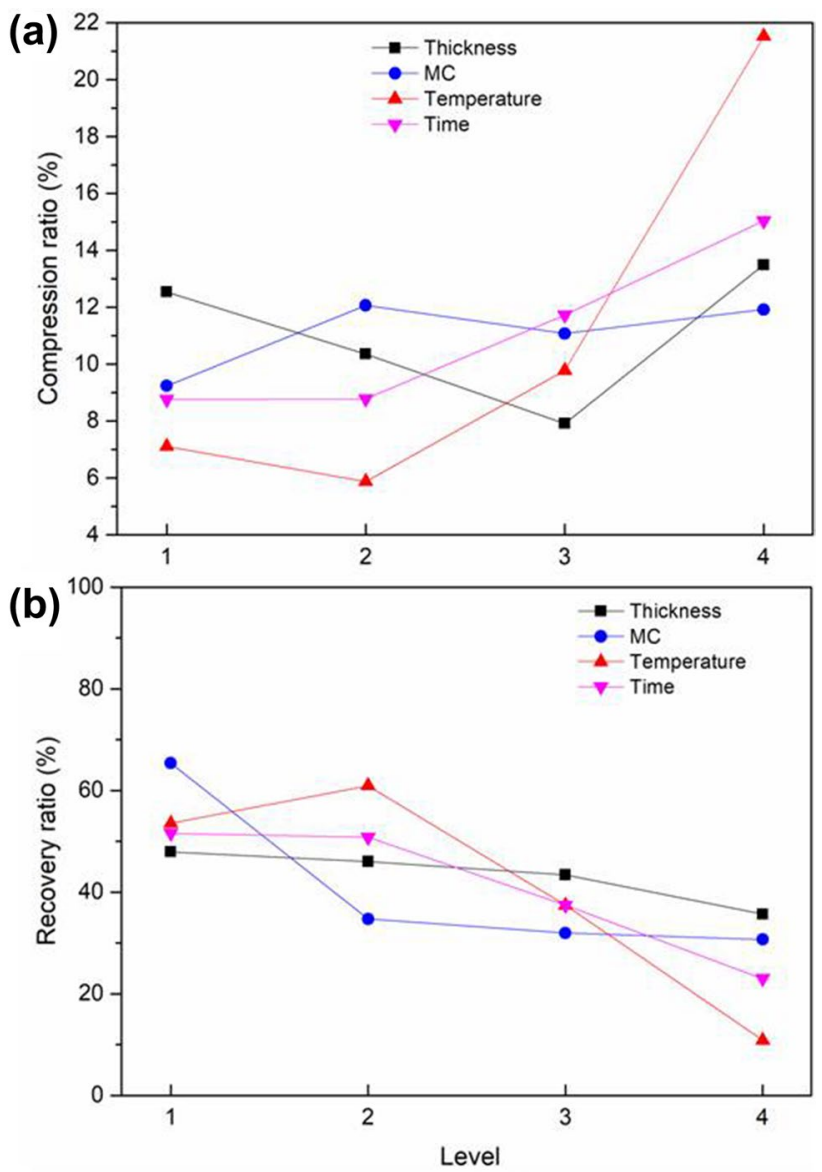

Fig. 3 Influence of variable levels on the compression and recovery ratios of bamboo. Note: level $1\left(0.9 \mathrm{~mm}, 4 \%, 120{ }^{\circ} \mathrm{C}, 10 \mathrm{~min}\right)$, level $2\left(2.3 \mathrm{~mm}, 8 \%, 150{ }^{\circ} \mathrm{C}, 20 \mathrm{~min}\right)$, level $3\left(3.6 \mathrm{~mm}, 12 \%, 180{ }^{\circ} \mathrm{C}\right.$, $30 \mathrm{~min})$, level $4\left(4.9 \mathrm{~mm}, 16 \%, 210{ }^{\circ} \mathrm{C}, 40 \mathrm{~min}\right) . M C$ moisture contents

to compression. The compression and recovery ratios of compressed bamboo with various MC did not show significant difference from each other except for $4 \% \mathrm{MC}$, at which the compression ratio was lowest and recovery ratio was highest. This indicated that keeping MC above $8 \%$ would facilitate compression and subsequent fixation.

\section{Visual observation of surface appearance}

The hot-press molding process had a similar effect on the bamboo color with heat treatment. Bamboo samples darkened with increased temperature (Fig. 4). When the temperature exceeded $150{ }^{\circ} \mathrm{C}$, the changes in color were quite apparent. At $210^{\circ} \mathrm{C}$, the color of bamboo turned from light yellow to black. The significant changes in color at high temperatures are probably due to lignin polymerization reactions, which produces intermediate lignin degradation compounds such as quinone and quinone [14]. Besides, transfer 


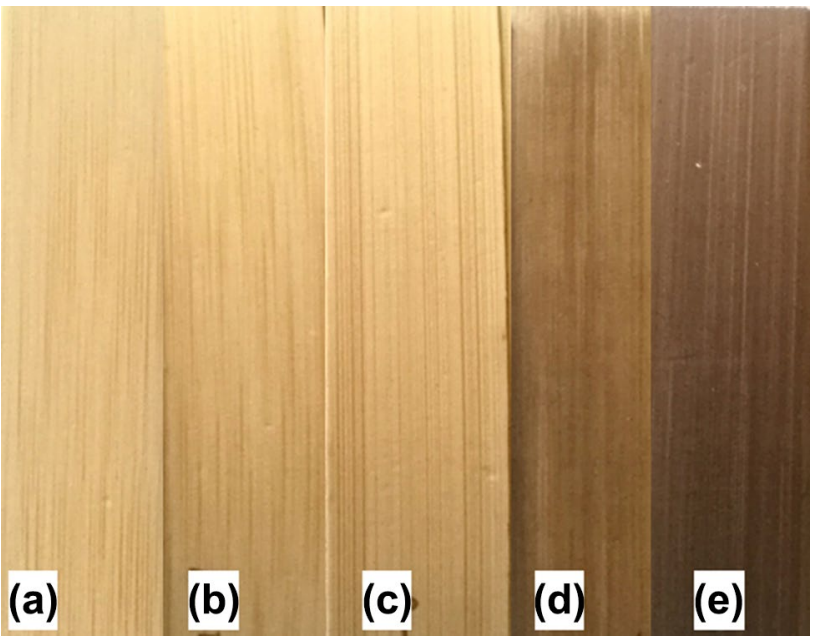

Fig. 4 Photographs of bamboo samples after compression: a untreated, b Group $8\left(120^{\circ} \mathrm{C}\right)$, c Group $11\left(150{ }^{\circ} \mathrm{C}\right)$, d Group 2 $\left(180{ }^{\circ} \mathrm{C}\right)$, e Group $13\left(210^{\circ} \mathrm{C}\right)$. Note The group number refers to Table 1

of carbohydrates and other extracts from the interior of sample to the exterior accompanied with the evaporation of moisture also attributed to the darkened color [15].

\section{Microstructure of compressed bamboo}

Micrographs of cross sections of bamboo before and after compression are shown in Fig. 5. The microstructure of bamboo culm consists of many vascular bundles embedded in parenchyma tissue. Densification of the parenchyma and closure of the vessels are evident for compressed bamboo from the micrographs. Most cells appeared to be deformed after compression. The parenchyma cells have undergone large plastic deformations without noticeable fracture or failure of the cell walls.

\section{Mass loss of compressed bamboo}

Mass loss of samples after hot-press moulding is presented in Table 1. Mass loss was less than 3.5\% when compressed at $120{ }^{\circ} \mathrm{C}$, which is mainly attributed to water evaporation in bamboo. The effect of heating condition on the mass loss of compressed bamboo shows that the mass loss increased with increasing temperature and heating time, and reached the maximum reduction of $7.8 \%$ when samples were compressed at $210{ }^{\circ} \mathrm{C}$ for $40 \mathrm{~min}$ (Table 1). ANOVA revealed that the influencing degree of four variables on mass loss decreased as: temperature $>$ time $>M C>$ thickness (Fig. 6).


Fig. 5 Scanning electron micrographs of cross section of $\mathbf{a}, \mathbf{b}$ untreated and $\mathbf{c}, \mathbf{d}$ compressed bamboo culm (Group 13). Note: the magnifications of the images are $\mathbf{a} \times 50, \mathbf{b} \times 150, \mathbf{c} \times 150, \mathbf{d} \times 150$, respectively 


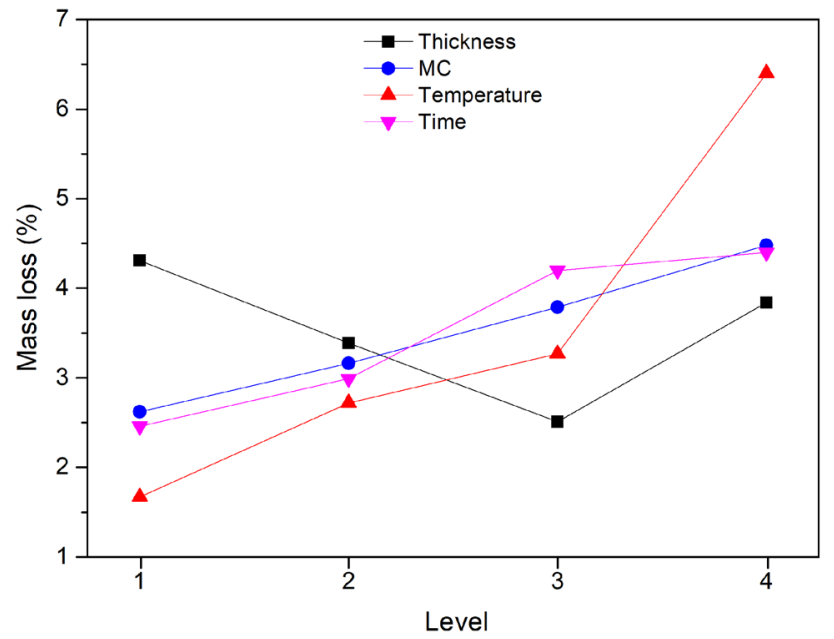

Fig. 6 Influence of variable levels on the mass loss of compressed bamboo. Note The level number refers to Fig. 3. MC moisture contents

The pressing temperature had a much greater effect on mass loss than did the other three factors. Starke et al. [16] also found that difference in the thermal treatment temperature induced a greater mass loss than an extension of the holding time. Mass loss varied greatly at four different temperature levels from 120 to $210{ }^{\circ} \mathrm{C}$. Zhang et al. [17] studied the effect of thermal treatment at temperature $100-220^{\circ} \mathrm{C}$ for 1- $4 \mathrm{~h}$ on bamboo. They found the sample remained stationary when heat treated below $160{ }^{\circ} \mathrm{C}$, and mass loss reached maximum of $29 \%$ when heat treated above $160{ }^{\circ} \mathrm{C}$ for $4 \mathrm{~h}$. Previous study by Zhong et al. [15] showed that $175{ }^{\circ} \mathrm{C}$ was a key turning point, at which thermal decomposition occurred in bamboo and the mass loss began to increase rapidly. Therefore, it is speculated that the mass loss of samples compressed at 180 and $210{ }^{\circ} \mathrm{C}$ is mainly due to the chemical components degradation.

\section{FTIR analysis}

Infrared spectra of control and compressed bamboo were compared to investigate the structural changes that occur during hot-press molding. Since the pressing temperature had a much greater effect on mass loss than did the other three factors, specimens compressed at 120,150, 180, and $210{ }^{\circ} \mathrm{C}$ for 40 min (Group 2, 8, 11 and 13) were selected for FTIR analysis. It has been reported that $\mathrm{C}-\mathrm{H}$ aliphatic stretching (around $2900 \mathrm{~cm}^{-1}$ ) is more stable than $\mathrm{C}-\mathrm{OH}$, $\mathrm{C}-\mathrm{O}-\mathrm{C}$, and $\mathrm{R}-\mathrm{COO}-\mathrm{R}$ bands and can be expected to stay intact during heat treatment [18]. Therefore, all the spectra were normalized to the absorption band around $2900 \mathrm{~cm}^{-1}$ which is chosen as a reference. The FTIR spectra of samples compressed at different temperatures in the studied region present similar patterns (Fig. 7).

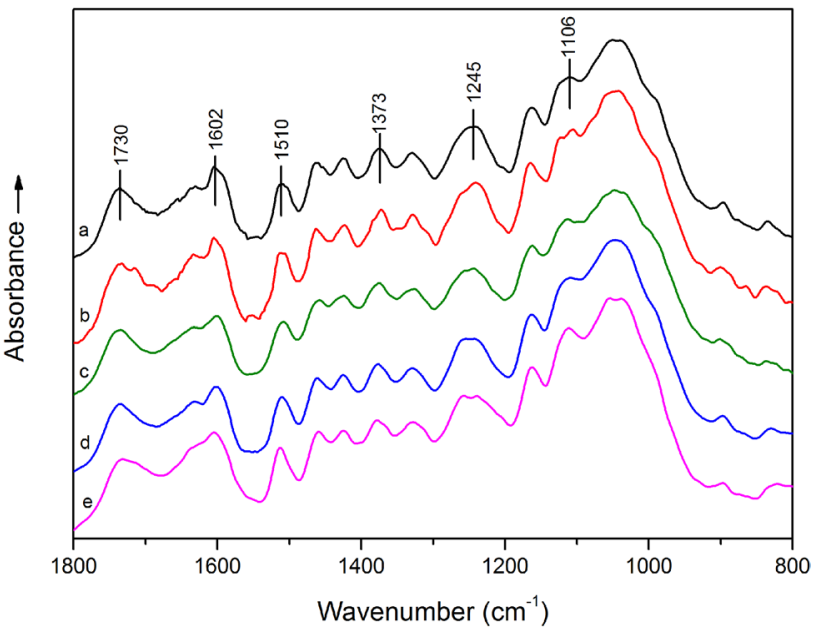

Fig. 7 FTIR spectra of compressed and control bamboo samples: a control, b Group $8\left(120{ }^{\circ} \mathrm{C}\right)$, c Group $11\left(150{ }^{\circ} \mathrm{C}\right)$, d Group 2 $\left(180{ }^{\circ} \mathrm{C}\right)$, and $\mathbf{e}$ Group $13\left(210^{\circ} \mathrm{C}\right)$

To further quantitatively evaluate the changes of chemical components at various pressing temperatures, the average relative intensities of peaks at 1730,1602,1510, 1373, 1245, and $1106 \mathrm{~cm}^{-1}$ against peak at $2900 \mathrm{~cm}^{-1}$ were calculated using peak heights, and the results are presented in Table 2 . There was no significant difference of the relative intensities of these characteristic bands between control and sample compressed at $120{ }^{\circ} \mathrm{C}$. However, the difference gradually became enlarged with increasing temperature, especially at 180 and $210^{\circ} \mathrm{C}$. Relative intensity of peak at $1730 \mathrm{~cm}^{-1}$, which is assigned to non-conjugated $\mathrm{C}=\mathrm{O}$ stretching in xylan of hemicellulose, decreased after compression at elevated temperature. This is probably caused by the preferential degradation of hemicelluloses over other components. The intensity of peaks at 1602 and $1510 \mathrm{~cm}^{-1}$ (aromatic skeletal vibrations of lignin) increased after treatment, indicating increase in relative contents of lignin. In addition, the relative intensity of peak at $1106 \mathrm{~cm}^{-1}$ that is attributed to $\mathrm{C}-\mathrm{H}$ stretching of aromatic ring in lignin also increased after compression. Similar trend has been previously observed by Meng et al. [18] who found that heat treatment led to an increase in relative contents of lignin due to reductions in polysaccharide contents. Relative intensities of the peak at $1373 \mathrm{~cm}^{-1}$, representing $\mathrm{C}-\mathrm{H}$ deforming and stretching of cellulose and hemicelluloses, decreased at 180 and $210{ }^{\circ} \mathrm{C}$. Another feature that needs to be taken into consideration is the decrease in the peak at $1245 \mathrm{~cm}^{-1}$ (guaiacyl ring breathing with CO-stretching of lignin and hemicellulose, esters) after treatment. This indicates the cleavage of acetyl groups in hemicelluloses, which form carbon acids, especially acetic acid. These results suggested that polysaccharide (especially hemicelluloses), whose branched structure and amorphous tissues are more susceptible to thermal degradation than 
Table 2 Ratio of the normalized heights of the absorption peaks of control and treated bamboo samples

\begin{tabular}{lllllll}
\hline Samples & $I_{1730} / I_{2900}$ & $I_{1602} / I_{2900}$ & $I_{1510} / I_{2900}$ & $I_{1373} / I_{2900}$ & $I_{1245} / I_{2900}$ & $I_{1106} / I_{2900}$ \\
\hline Control & 1.03 & 1.45 & 0.92 & 0.55 & 1.14 & 0.40 \\
Group $8\left(120^{\circ} \mathrm{C}\right)$ & 1.04 & 1.44 & 0.93 & 0.53 & 1.15 & 0.38 \\
Group $11\left(150^{\circ} \mathrm{C}\right)$ & 1.05 & 1.46 & 0.96 & 0.48 & 1.07 & 0.43 \\
Group 2 $\left(180^{\circ} \mathrm{C}\right)$ & 1.00 & 1.47 & 1.00 & 0.46 & 1.05 & 0.50 \\
Group $13\left(210^{\circ} \mathrm{C}\right)$ & 0.98 & 1.49 & 1.17 & 0.37 & 1.03 & 0.76 \\
\hline
\end{tabular}

The heat treatment time for all these samples is $40 \mathrm{~min}$

$I_{1730} / I_{2900,} I_{1602} / I_{2900,} I_{1510} / I_{2900}, I_{1373} / I_{2900}, I_{1245} / I_{2900}$, and $I_{1106} / I_{2900}$ refer to the average relative intensities of peaks at $1730,1602,1510,1373,1245$, and $1106 \mathrm{~cm}^{-1}$ against peak at $2900 \mathrm{~cm}^{-1}$, respectively

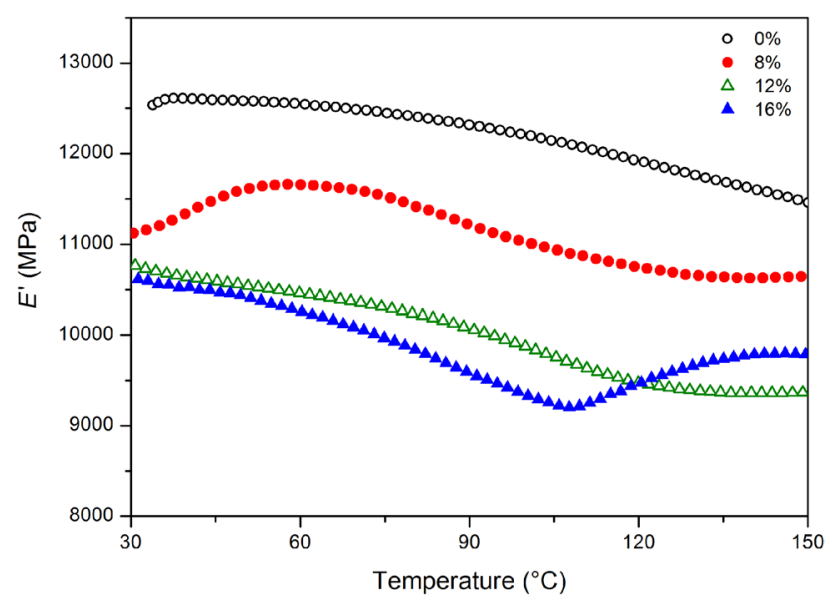

Fig. 8 Storage modulus $\left(E^{\prime}\right)$ of bamboo samples with different moisture contents

other components [19], underwent a progressive degradation during compression at 180 and $210^{\circ} \mathrm{C}$. This finding is in agreement with the mass loss data.

\section{DMA}

To clarify the role of MC during the mold pressing, bamboo specimens with different MC were subjected to DMA measurement. Storage modulus $\left(E^{\prime}\right)$ values of samples, which are related to the ability of storing mechanical energy, are plotted as functions of temperature (Fig. 8). The general feature of $E^{\prime}$ variation with temperature for bamboo samples is similar to those observed in previous studies of wood [20, 21]. The decrease of the $E^{\prime}$ value of all samples with increasing temperature was attributed to the higher chain mobility of cell wall components at elevated temperature. At low temperature region, the kinetic energy of material molecules is very low, with motion occurring only in some small units such as side and branched chains. High temperature could result in crystallization or ordering of the molecules, causing the substantial decrease of $E^{\prime}$ [22]. It should be noted that, for sample with $16 \% \mathrm{MC}$, the $E^{\prime}$ gradually increased from around $100{ }^{\circ} \mathrm{C}$. One probable reason is the MC decreased with temperature increase. Because the DMA equipment used in this research lacks relative humidity control, and water started to evaporate from the samples when they were heated up to $100{ }^{\circ} \mathrm{C}$. Over the entire temperature range, the bamboo with a higher MC generally had a lower $E^{\prime}$ value, indicative of a lower relevant stiffness. Liu et al. [22] also found the storage modulus decreased with water content increase. This phenomenon confirmed the expected role of water as having a plasticizing effect on the bamboo.

Loss factor $(\tan \delta$ ) measurements provided information on transitions of the material. At low MC (0 and 8\%) there was no detectable transition during the tested temperature range $\left(30-150{ }^{\circ} \mathrm{C}\right)$ (Fig. 9). Previous study shows that dry wood exhibits only very weak secondary relaxations between -150 and $150{ }^{\circ} \mathrm{C}$, because under this condition the in situ $T_{\mathrm{g}}$ values for hemicellulose, lignin and amorphous cellulose occur at above $150{ }^{\circ} \mathrm{C}$ [23]. The bamboo materials with 12 and $16 \%$ MC exhibited two transitions: one transition centred around $100{ }^{\circ} \mathrm{C}\left(\alpha_{1}\right)$; and the other between 30 and $60{ }^{\circ} \mathrm{C}\left(\alpha_{2}\right)$. Similar results have been previously observed by Liu et al. [22] who found that $\alpha_{1}$ transition occurred around $80{ }^{\circ} \mathrm{C}$ and $\alpha_{2}$ transition around $30^{\circ} \mathrm{C}$ for moso bamboo with 8 and $12 \%$ MC. The $\alpha_{1}$ and $\alpha_{2}$ transitions are probably linked to the glass-rubber transition of lignin and hemicelluloses, respectively. The presence of water has been found to plasticize cell wall components, causing a reduction of energy required to initiate chain mobility. Consequently, the precise temperature of $\alpha$ transitions is expected to vary with MC. However, in this study the temperature of $\alpha$ transitions kept almost unchanged as moisture level increased from 12 to $16 \%$. The sensitivity of these transitions to moisture complicated the DMA analysis since the relative humidity of the sample chamber is difficult to control. It should be noted that the $\alpha_{1}$ transition of sample with $16 \%$ MC occurred in a broader range than $12 \%$, most likely due to the loss of moisture in the sample during the scan. It has been reported in the literature that moisture loss can lead to a broadening of the $\tan \delta$ response, an effect which would be most pronounced for samples with a transition around $100{ }^{\circ} \mathrm{C}$ [20]. 

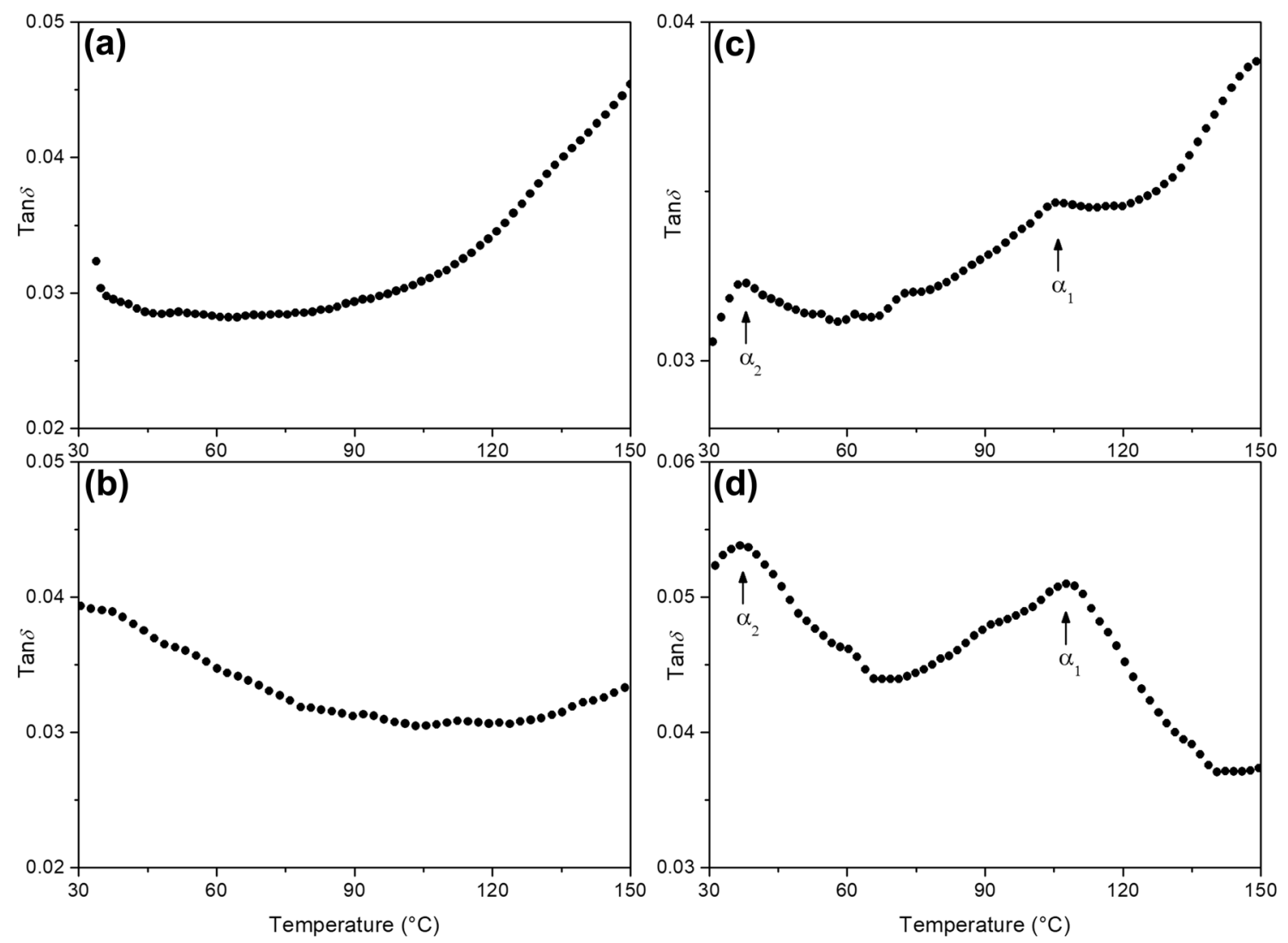

Fig. 9 Loss factor $\left(\tan \delta\right.$ ) of bamboo samples with different moisture contents: a $0 \%$, b $8 \%$, c $12 \%$, d $16 \%$. Note $\alpha_{1}$ refers to the transition centred on $90-110^{\circ} \mathrm{C}$ and $\alpha_{2}$ refers to the transition centred on $30-60{ }^{\circ} \mathrm{C}$, respectively

\section{Conclusion}

For manufacturing profiled bamboo components that can be used in structural or engineered products, it is essential to understand the deformation and softening behaviour of curved bamboo. The presented work investigated the influence of variables including thickness, MC, hot-press temperature and time on the compression of curved moso bamboo during hot-press molding. Experimental results indicated that temperature had the most prominent effect on the compression and recovery ratios of bamboo, followed by time, thickness and MC. Generally, pressing at higher temperature $\left(180\right.$ and $210{ }^{\circ} \mathrm{C}$ ) for longer time (30 and $40 \mathrm{~min}$ ) resulted in higher compression ratio, as well as lower recovery ratio after equilibrium. This is related to the preferential thermal degradation of cellulose and hemicelluloses. Keeping MC of bamboo above $8 \%$ would facilitate compression and subsequent fixation, attributed to the plasticizing effect of water. No significant difference for the glass-rubber transition temperatures of cell wall components was observed as moisture level increased from 12 to $16 \%$. This is probably due to that the DMA equipment used in this research lacks relative humidity control of the sample chamber.
Acknowledgements The authors acknowledge the sponsorship from Special Fund of Chinese Academy of Forestry for Fundamental Scientific Research (No. CAFYBB2014MA009).

\section{Compliance with ethical standards}

Conflict of interest The authors declare that they have no conflict of interest.

\section{References}

1. Dixon PG, Semple KE, Kutnar A, Kamke FA, Smith GD, Gibson LJ (2016) Comparison of the flexural behavior of natural and thermo-hydro-mechanically densified moso bamboo. Eur J Wood Wood Prod 74(5):633-642

2. Kaur PJ, Kardam V, Pant KK, Naik SN, Satya S (2015) Characterization of commercially important Asian bamboo species. Eur J Wood Wood Prod 74(1):137-139

3. Amada S, Ichikawa Y, Munekata T, Nagase Y, Shimizu H (1997) Fiber texture and mechanical graded structure of bamboo. Compos Part B Eng 28(1):13-20

4. Ito Y, Tanahashi M, Shigematsu M, Shinoda Y (1998) Compressive-molding of wood by high-pressure steam-treatment: part 2 . Mechanism of permanent fixation. Holzforschung 52(2):217-221 
5. Kariz M, Kuzman MK, Sernek M, Hughes M, Rautkari L, Kamke FA, Kutnar A (2017) Influence of temperature of thermal treatment on surface densification of spruce. Eur J Wood Wood Prod 75(1):113-123

6. Yamashita O, Yokochi H, Miki T, Kanayama K (2009) The pliability of wood and its application to molding. J Mater Process Technol 209(12-13):5239-5244

7. Sandberg D, Haller P, Navi P (2013) Thermo-hydro and thermohydro-mechanical wood processing: an opportunity for future environmentally friendly wood products. Wood Mater Sci Eng 8(1):64-88

8. Endo K, Obataya E, Zeniya N, Matsuo M (2016) Effects of heating humidity on the physical properties of hydrothermally treated spruce wood. Wood Sci Technol 50(6):1161-1179

9. Kutnar A, Kamke FA (2011) Influence of temperature and steam environment on set recovery of compressive deformation of wood. Wood Sci Technol 46(5):953-964

10. Laine K, Rautkari L, Hughes M, Kutnar A (2012) Reducing the set-recovery of surface densified solid Scots pine wood by hydrothermal post-treatment. Eur J Wood Wood Prod 71(1):17-23

11. Norimoto M, Ota C, Akitsu H, Yamada T (1993) Permanent fixation of bending deformation in wood by heat treatment. Wood Res 79:23-33

12. Zhao Y (2017) Studies on pre-treatment by compression for wood drying III: the reduction of moisture content, the recovery rate, and mechanical properties of wood compressed at different moisture content conditions. J Wood Sci 63(3):209-215

13. Grosser D, Liese W (1971) On the anatomy of Asian bamboos, with special reference to their vascular bundles. Wood Sci Technol 5(4):290-312
14. Fang C-H, Mariotti N, Cloutier A, Koubaa A, Blanchet P (2012) Densification of wood veneers by compression combined with heat and steam. Eur J Wood Wood Prod 70(1-3):155-163

15. Zhong Y, Ren HQ, Jiang ZH (2016) Effects of temperature on the compressive strength parallel to the grain of bamboo scrimbe. Materials 9(6):436

16. Starke R, Rosenthal M, Bues C-T, Bremer M, Fischer S (2016) Thermal modification of African alpine bamboo. Eur J Wood Wood Prod 74(6):901-903

17. Zhang YM, Yu YL, Yu WJ (2012) Effect of thermal treatment on the physical and mechanical properties of Phyllostachys pubescen bamboo. Eur J Wood Wood Prod 71(1):61-67

18. Meng FD, Yu YL, Zhang YM, Yu WJ, Gao JM (2016) Surface chemical composition analysis of heat-treated bamboo. Appl Surf Sci 371:383-390

19. Shangguan W, Gong Y, Zhao R, Ren H (2016) Effects of heat treatment on the properties of bamboo scrimber. J Wood Sci 62(5):383-391

20. Kelley SS, Rials TG, Glasser WG (1987) Relaxation behaviour of the amorphous components of wood. J Mater Sci 22(2):617-624

21. Guo J, Yin J, Zhang Y, Salmén L, Yin Y (2017) Effects of thermohygro-mechanical (THM) treatment on the viscoelasticity of insitu lignin. Holzforschung 71(6):455-460

22. Liu ZJ, Jiang ZH, Cai ZY, Fei BH, Yan Y, Liu XE (2012) Dynamic mechanical thermal analysis of moso bamboo (Phyllostachys heterocycla) at different moisture content. Bioresources 7(2):1548-1557

23. Sun N, Das S, Frazier CE (2007) Dynamic mechanical analysis of dry wood: Linear viscoelastic response region and effects of minor moisture changes. Holzforschung 61(1):28-33 